\title{
An Examination of the Precipitation Delivery Mechanisms for Dolleman Island,
}

\section{Eastern Antarctic Peninsula}

\author{
Andrew Russell* \\ University of Birmingham, Department of Geography, Earth and Environmental \\ Sciences, Edgbaston, Birmingham, B15 2TT, UK
}

Glenn R. McGregor

University of Birmingham, Department of Geography, Earth and Environmental

Sciences, Edgbaston, Birmingham, B15 2TT, UK

\author{
Gareth J. Marshall
}

British Antarctic Survey, Natural Environment Research Council, High Cross, Madingley Road, Cambridge, CB3 OET, UK

* Corresponding author email: axr141@bham.ac.uk andrew.russell@brunel.ac.uk 


\begin{abstract}
The variability of size and source of significant precipitation events were studied at an Antarctic ice core drilling site: Dolleman Island (DI), located on the eastern coast of the Antarctic Peninsula. Significant precipitation events that occur at DI were temporally located in the ECMWF re-analysis data set, ERA-40. The annual and summer precipitation totals from ERA-40 at DI both show significant increases over the re-analysis period. Three dimensional backwards air parcel trajectories were then run for 5-days using the ECMWF ERA-15 wind fields. Cluster analyses were performed on two sets of these backwards trajectories: all days in the range 1979-1992 (the climatological timescale) and a subset of days when a significant precipitation event occurred. The principal air mass sources and delivery mechanisms were found to be the Weddell Sea via lee cyclogenesis, the South Atlantic when there was a weak Circumpolar Trough (CPT) and the South Pacific when the CPT was deep. The occurrence of precipitation bearing air masses arriving via a strong CPT was found to have a significant correlation with the Southern Annular Mode (SAM), however, the arrival of air masses from the same region over the climatological timescale showed no such correlation. Despite the dominance in both groups of back trajectories of the westerly circulation around Antarctica, some other key patterns were identified. Most notably there was a higher frequency of lee cyclogenesis events in the significant precipitation trajectories compared to the climatological timescale. There was also a tendency for precipitation trajectories to come from more northerly latitudes, mostly from 50$70^{\circ} \mathrm{S}$. ENSO was found to have a strong influence on the mechanism by which the precipitation was delivered; the frequency of occurrence of precipitation from the east (west) of DI increased during El Niño (La Niña) events.
\end{abstract}

Key Words: Antarctic Peninsula, ECMWF re-analysis, backwards air trajectories, precipitation 


\section{Introduction}

Over the last 50 years, meteorological observations from the western Antarctic Peninsula demonstrate that the region has undergone one of the largest temperature changes reported anywhere on the globe. For example, since 1951 the annual mean temperature at Faraday station (Figure 1) has risen by $\sim 3^{\circ} \mathrm{C}$ (see http://www.antarctica.ac.uk/met/gjma/ for Antarctic surface temperature data), while Vaughan et al. (2001), have shown significant positive annual temperature trends at other western Antarctic Peninsula stations. On the north-eastern side of the peninsula, smaller increases in annual mean temperature over a 50-year period have been observed at Esperanza, but perhaps more importantly, the summer mean temperature increase for this location is approximately twice the magnitude of the summer warming seen on the western side of the peninsula (Skvarca et al., 1998). Such dramatic summer warming has occurred in parallel with the demise of the Larsen Ice Shelf (Doake et al., 1998; Rott et al., 2002), which may have led to an acceleration and consequent decline in mass of the glaciers of western Antarctica (De Angelis and Skvarca, 2003). In order to place recent observed increases in temperature in a regional and global palaeoclimatic context, proxy records of temperature are extracted from ice cores (Folland et al., 2001). This method is of particular use in the data sparse Antarctic and there have been 6 drilling sites studied on the relatively easily accessible peninsula region (Peel, 1992; Mulvaney et al., 2002). This reconstruction of past climate is made possible due to the effect that temperature has upon the isotopic balance in the moisture that arrives at Antarctica as precipitation (Legrand and Mayewski, 1997). However, the source of and the atmospheric route taken by this moisture will also influence the chemical composition and, more importantly, the isotopic ratios recorded in these ice cores. Delaygue et al. (2000a) have used GCM data to study these effects on central Antarctic precipitation and conclude that the effects of precipitation seasonality and the cooling of moisture sources have a limited and opposite effect and are, therefore, thought to not influence the validity of the "isotopic thermometer" for central Antarctica. However, the mechanisms by which precipitation is formed and delivered to the Antarctic coast and, in particular, the Antarctic Peninsula are quite different from central Antarctica because of the proximity to the Circumpolar Trough (CPT) and the synoptic systems therein (King and Turner, 1997; Turner et al., 1998; Simmonds et al., 2003). This results in increased precipitation quantity and variability at coastal and peninsula sites but does not have a particularly large effect on the Antarctic interior. These factors may have implications for the interpretation of the regional proxy climatic records contained within coastal and peninsula ice cores. For example, Schlosser (1999) suggested that variability in the position of the CPT has had a significant effect on the Neumayer $\delta^{18} \mathrm{O}$ record (this station is in Dronning Maud Land (DML), located to the east of the Weddell Sea). For the period 1982-1991 the Neumayer $\delta^{18} \mathrm{O}$ record implied that the temperature varied in the order of $5^{\circ} \mathrm{C}$ when the observed variability from the station itself for the same period was less than $1{ }^{\circ} \mathrm{C}$. In addition, Noone et al. (1999) studied the signals from atmospheric circulation that could be detected in the accumulation of an Antarctic ice core, again from DML. They conclude that the glaciological record is connected to global atmospheric circulation characteristics and could, thus, be used as a tool in reconstructing past atmospheric circulation changes.

With this point in mind, a variety of methods that have been used to identify the source of Antarctic precipitation will now be discussed. Ciais et al. (1995) concluded from a study of snow deuterium excess data from a South Pole snow pit that the dominant moisture source for this precipitation was $20-40^{\circ} \mathrm{S}$. This result is in partial disagreement with the low resolution GCM $\left(8^{\circ} \times 10^{\circ}\right)$ based findings of Delaygue et al. (2000b) who reported that moisture from $30-60^{\circ} \mathrm{S}$ plays a significant role in the precipitation climatology of Antarctica 
as a whole. Bromwich and Weaver (1983) investigated the $\delta^{18} \mathrm{O}$ record for 1974 from the coastal station Syowa $\left(69^{\circ} \mathrm{S}, 39^{\circ} \mathrm{E}\right)$ and inferred that the moisture source was around $55-58^{\circ} \mathrm{S}$. Further, Reijmer et al. (2002) analysed air parcel back trajectories for a number of ice core sites from eastern Antarctica and the western Antarctic ice sheet. They found that the main moisture sources for all sites were located in the latitude range of $50-60^{\circ} \mathrm{S}$ from the nearest ocean to the west of the site in question. These studies of precipitation source for continental Antarctica tend to have found the source to be further north than Turner et al. (1995), who examined the precipitation sources for Rothera station, located on the western Antarctic Peninsula (Figure 1). Using meteorological observations and satellite imagery for a one year period, Turner et al. (1995) concluded that half of the cyclones that deliver precipitation to Rothera develop south of the $60^{\circ} \mathrm{S}$ parallel. Peel and Mulvaney (1992) are the only workers to consider the source of precipitation for the eastern Antarctic Peninsula. They studied the chemical composition of an ice core from Dolleman Island, eastern Antarctic Peninsula, and concluded that the marginal ice zone of the Weddell Sea has become an important source of moisture for this region over recent times. However, their results could be questioned with respect to one of their assumptions i.e. that an increase in non-sea salt sulphate $\left(\mathrm{nsSSO}_{4}{ }^{2-}\right)$

concentration is an indication of increased open sea. It has since been argued that $\mathrm{nsSSO}_{4}{ }^{2-}$ in this region is largely derived from "frost flowers" that form on new sea ice (Rankin et al., 2002; Wolff et al., 2003). If this is correct, it implies that Peel and Mulvaney's (1992) assumption would need to be reversed.

Given this debate concerning the origin of the moisture that results in Antarctic precipitation and the relative lack of work examining the eastern Antarctic Peninsula, the purpose of this study is to examine the precipitation delivery mechanisms for Dolleman Island $\left(70.3^{\circ} \mathrm{S}\right.$, $60.5^{\circ} \mathrm{W}$; hereafter DI) on the eastern side of the Antarctic Peninsula (Figure 1). This was achieved by undertaking an air parcel backwards trajectory analysis of the precipitation record contained within a re-analysis data set and an ice core drilled on the island in 1993.

Section 2 of this paper will briefly describe the data and methods employed in this study. As background, the precipitation regime of DI will be discussed in Section 3. Section 4 presents the results of the back trajectory analysis. The implications of the analysis results will be discussed and conclusions drawn in Section 5.

\section{Data and Methodology}

An environment to circulation approach (Yarnal et al., 2001) was used here to elucidate the large-scale precipitation delivery mechanisms to DI. Firstly, "significant" precipitation events (i.e. the largest precipitation events) were identified at the daily timescale. Secondly, 5-day back trajectory analyses for the dates associated with these events were preformed in order to identify the source regions and trajectories of the air masses bearing the precipitation. A comparative analysis between the back trajectory patterns for the significant precipitation events and the climatological pattern for the study was then made. Finally, the annual accumulation for DI, as recorded in an ice core drilled in 1993 and forecast by reanalysis data, were analysed in relation to the inter-annual variability of the back trajectory patterns.

In this study European Centre for Medium Range Weather Forecasting (ECMWF) 44-year re-analysis data (ERA-40) were utilized to examine the general precipitation regime at DI for the period 1958-2001. However, within this period the years of 1979-1992 were focused 
upon as 1992 represents the last year of the DI ice core based annual accumulation record. Moreover, at the time of writing, back trajectory analysis was only completed using the older ECMWF re-analysis dataset, ERA-15, which is only available from 1979. It is considered that there is no methodological problem in using these two datasets in this way because there is a very high degree of correlation between the pressure data fields for the whole of the Southern Hemisphere between ERA-40 and ERA-15. Figure 2 shows the case for mean sea level pressure (MSLP). Therefore the back trajectories derived from the two re-analyses will also be correlated to a significant degree.

The precipitation field in ERA-40 was calculated as a daily forecast. The most accurate method (i.e. the method that most reduces the spin-up error) of calculating this daily forecast is thought to be the sum of (i) the difference between the $(T+12)$ and $(T+24)$ forecasts, where $\mathrm{T}$ is $1200 \mathrm{hrs}$ on the previous day and (ii) the equivalent value calculated where $\mathrm{T}$ is 0000hrs on the day in question (Genthon and Krinner, 1998). It is also assumed that the daily precipitation forecast total represents one precipitation event.

With respect to verifying the ERA-40 data for the study period at DI, we can examine the temperature and atmospheric pressure data recorded by an Automatic Weather Station (AWS) that was located on DI between 1986 and 1988. Figure 3 shows a plot of temperature for this period from both the AWS and the ERA-40 data. The correlation co-efficient between the AWS and the ERA-40 data for temperature and surface pressure from the closest model grid cell are 0.93 and 0.94 respectively, both of which are significant at the 0.01 level. These correlations imply that the ERA-40 data can be used to portray the general climatology at DI with reasonable confidence. The Root Mean Squared (RMS) errors between the AWS and ERA-40 data are $2.9^{\circ} \mathrm{C}$ and $4.8 \mathrm{hPa}$. In order to calculate these RMS errors the differences in height of DI in reality and in the model were accounted for. The temperature was corrected by using a factor that reflects the sensitivity of temperature to altitude as described by Krinner and Genthon (1999) and the pressure was corrected using the hydrostatic equation. The difference that remains is likely to be due, in part, to the smoothing of the peninsula topography and the partially related inaccuracies in the land/sea mask of the model.

However, the most important data field for this study is precipitation and it should be borne in mind that precipitation fields are derived and also difficult to validate. Despite this, some workers have assessed the quality of the ECMWF re-analysis precipitation data on a continental scale for Antarctica. For example, Genthon and Braun (1995) describe the mean annual Antarctic precipitation from the older and shorter ECMWF re-analysis, ERA-15 as being "fairly well represented". Further, Genthon and Cosme (2003) show that ERA-40 continental scale Antarctic mean surface mass balance is in "relative agreement" with glaciological measurements from Vaughan et al. (1999). Genthon (2003) also believes ERA40 precipitation and, especially, evaporation data to be more realistic than ERA-15 due to less spin up problems in the newer model. Indeed, there is noticeable difference between the time series of precipitation from the two re-analyses at DI. For these reasons, the ERA-40 precipitation data was assumed to be more reliable and was used in this study despite using back trajectories driven by the ERA-15 data. 
It should also be noted at this stage that the reliability of major data fields in the ERA-40 reanalysis (MSLP, 2m-temperature and $500 \mathrm{hPa}$ geopotential height) have been seriously questioned in the southern high-latitudes. Bromwich and Fogt (2004) have highlighted some very low and even some negative correlations between Antarctic station and ERA-40 data for the period before the introduction of satellite observations ( 1972), especially in winter. This is followed by a rapid increase in ERA-40 skill up to the dawn of the satellite era. In summer, though, the high-latitude data was found to be of a comparable quality as that from the mid latitude Southern Hemisphere continents. Despite the largest of these problems being discovered in eastern Antarctica, there are still significant problems with the ERA-40 data over the Antarctic Peninsula. The implications of Bromwich and Fogt's (2004) work are that any ERA-40 data used before the early 1970s must be seriously scrutinised in this study.

Although it is impossible to verify the daily DI precipitation from ERA-40, a comparison can be made between the annual accumulation record from ERA-40 (precipitation minus evaporation or P-E) and the surface mass balance (SMB) data contained in the DI ice core. Firstly, though, given that Pasteur and Mulvaney (2000) show that there is only "occasional slight melting" in the DI core, and that the summer melt period for the DI area, as determined by Torinesi et al. (2003) from microwave sensors, is relatively short, it is noted here that SMB is assumed to be equal to accumulation for DI in this paper. This provides an opportunity for verification of accumulation at the annual timescale. In order to perform such a comparison, the ERA-40 annual P-E totals were calculated over the twelve month period of August to July, rather than the calendar year, as this former period coincides with the ice core's annual cycle of isotopic stratigraphy that was used to divide the ice core into annual layers (Peel et al., 1988). Overall, the annual ERA-40 and ice core accumulation demonstrate a weak $(\mathrm{r}=0.29)$ and statistically insignificant association over the full overlap period of 1958-1992 (Figure 4). The serious problems associated with the ERA-40 data before the introduction of satellite observations (Bromwich and Fogt, 2004) have undoubtedly had an impact here. Despite this, examination of Figure 4 reveals that for the period covered by the air parcel trajectory study (1979-1992) the general upward trend in ERA-40 and ice core annual accumulation is similar. Furthermore, there is a higher degree of statistical association between the ERA-40 P-E and ice core accumulation for this latter period $(\mathrm{r}=$ $0.59, \mathrm{p}=0.05)$.

As noted earlier, back trajectory (hereafter BT) analyses were conducted for days with significant precipitation and all days over the period 1979-1992 (the climatological timescale). Figure 5 shows the frequency of ERA- 40 precipitation events by size. It is clear that ERA-40 precipitation at DI is dominated by small events and this is possibly an unlikely characteristic. Although there is no precipitation data from the DI AWS to confirm this, it has been shown by Reijmer et al. (2002) for an Antarctic site in Dronning Maud Land (DML) that the dominance of small precipitation events in the re-analysis is unrealistic; when compared to sonic altimeter measurements from their site is was shown that only the larger events in the re-analysis data occurred in reality. However, the DML site investigated by Reijmer et al. (2002) is at a much greater altitude than DI and is some distance away on the opposite side of the Weddell Sea, therefore, the two sites may display significantly different precipitation characteristics. Indeed, Turner et al. (1997) used synoptic observations to 
describe a very different situation on the western Antarctic Peninsula: they report that the mean number of precipitation events at Rothera (Figure 1) for the period 1956-1994 is 463 per year. These studies of DML and western Antarctic Peninsula precipitation represent the nearest and most relevant works on precipitation regime in western Antarctica. However, Figure 6 shows that for the ERA-40 data there is a relatively low correlation co-efficient between the DI precipitation regime and the areas studied by Reijmer et al. (2002) and Turner et al. (1997). Taking the differing precipitation regimes of these two sites into account, this paper is, as a result, concerned with the investigation of air mass trajectories that are associated with both the climatological timescale and the days that received a significant amount of precipitation in the re-analysis. Given this, a significant precipitation event at DI was defined in this study as the largest events in the data set, namely, days that receive more than $3.57 \mathrm{~mm}$ of precipitation (Figure 5). This threshold was chosen as, collectively, precipitation events larger than $3.57 \mathrm{~mm}^{-1 a y^{-1}}$ are responsible for $50 \%$ of the total ERA-40 precipitation at DI. This threshold is broken on 654 days, which represents $12.8 \%$ of the study period 1979-1992.

The BT analysis was run using the British Atmospheric Data Centre (www.badc.rl.ac.uk) trajectory model. This model derives three dimensional air parcel paths from a set of wind components $(u, v$, omega $)$ held on a $2.5^{\circ}$ x $2.5^{\circ}$ latitude/longitude grid and uses ECMWF ERA-15 six hourly pressure data. Again, it was deemed to be acceptable to use the ERA-15 data for the BTs as there was found to be a relatively high degree of correlation between the temporal occurrence of significant precipitation events in ERA-40 and ERA-15 (Spearman's rank correlation of $\mathrm{r}=0.75, \mathrm{p}=0.01$ ). Therefore, the ERA-15 trajectories were very likely to capture the characteristics of the precipitation events. The BTs were initiated at the $850 \mathrm{hPa}$ level starting at $1200 \mathrm{hrs}$ from $70.3^{\circ} \mathrm{S}, 60.5^{\circ} \mathrm{W}$ and output data at six hourly intervals for 5 days. The initial level of $850 \mathrm{hPa}$ was chosen as this exceeds the elevation of DI $(398 \mathrm{~m})$ but is still low enough to be directly influenced by the smoothed Antarctic Peninsula topography in the model (Turner et al., 1999). As a wide variety of BTs were found to exist for the climatological timescale and for the days comprising significant precipitation events, individual BTs were grouped using hierarchical cluster analysis, based on Ward's solution, in order to identify the major BT patterns. The number of BT groups retained for analysis was determined by inspection of the cluster analysis dendrogram and by consideration of the rate of decay of an agglomeration coefficient that portrays the rate at which large numbers of small groups are aggregated into a smaller number of large groups. The resultant BT pattern groups for the significant precipitation events were subsequently compared with the climatological pattern (all days).

\section{Precipitation Regime}

The precipitation regime of the Antarctic Peninsula is largely defined by its position and topography. The western side experiences a relatively warm, maritime climate due to its protrusion into lower latitudes and, thus, into the prevalent westerly, circumpolar atmospheric circulation. The elevation of the peninsula (typically $2 \mathrm{~km}$ ) and the steep orography results in the triggering of precipitation on the western side. The elevation also has the effect of shielding the eastern side from most of the weather systems approaching the peninsula from the west. This leads to a very different temperature and precipitation regimes on the two 
sides of the peninsula and Figure 6 illustrates this latter point. This figure shows that the ERA-40 precipitation at DI has a higher correlation with that over the Weddell Sea than with the western Antarctic Peninsula and a negative correlation further to the west over the Amundsen and Bellingshausen Seas (ABS). Such climate contrasts are also seen in the annual cycle of precipitation across the Peninsula. Figure 7 shows that there is a summer peak in the ERA-40 precipitation at DI whereas there is a winter peak at most western Antarctic Peninsula locations (King and Turner, 1997).

Regression analysis of the seasonal precipitation from ERA-40 against time (independent variable) revealed that only summer has a statistically significant positive trend at DI $\left(\mathrm{r}^{2}=\right.$ $0.45, \mathrm{p}=0.01$ ). This positive trend in summer precipitation (Figure 8 ) is chiefly responsible for the positive trend seen in the ERA-40 annual accumulation totals (Figure 4). This has occurred as a result of an increase in the size of the summer precipitation events in the reanalysis data. This is supported by the fact that there is no significant trend or inter-annual variation in the mean annual significant precipitation event size or frequency per year in the ERA-40 precipitation (not shown). However the trend to higher summer (DJF) precipitation totals seen in the re-analysis appears not to be associated with summer warming, as summer temperatures for this area from ERA-40 (Figure 8) do not demonstrate a comparable trend. It must be borne in mind, that despite the major shortcomings in this data before $\sim 1972$ occurring in non-summer months (Bromwich and Fogt, 2004) these problems may still impact the data discussed above. Interestingly, the absence of marked summer warming contrasts with the trends found within the observational record for Esperanza, which is also located in eastern Antarctic Peninsula (Skvarca et al., 1998). This difference is probably related to the fact that Esperanza is much further north than DI. Esperanza is, however, the only eastern Antarctic Peninsula station to have a temperature record of reasonable quality and length.

As noted in Section 2, both ERA-40 and the ice core demonstrate an increase in annual accumulation at DI over the period 1979-1992 (Figure 4). Of note is the considerable level of inter-annual variability imposed on the positive trend of accumulation, particularly evident in the ice core data. Assuming all other things being equal, it may be speculated that the annual accumulation is sensitive to the inter-annual variability of air mass trajectories such that high accumulation years will possess basic BT pattern differences compared to low accumulation years. This contention is investigated in the next section.

\section{Back Trajectory Analysis}

BT cluster analysis for all days over the period 1979-92 revealed eight predominant air mass trajectory groups (Figure 9). These will be referred to as the climatological or $\mathrm{BT}_{\mathrm{cl}}$ patterns. Although there are eight climatological patterns, it is likely that $\mathrm{BT}_{\mathrm{cl}} 6-8$ are a subgroup of $\mathrm{BT}_{\mathrm{cl}} 5$ as they essentially possess the same trajectory characteristics apart from an origin further to the west of $\mathrm{BT}_{\mathrm{cl}} 5$. For the subgroup of $\mathrm{BT}$ patterns associated with the 654 significant precipitation $\left(\mathrm{BT}_{\mathrm{sp}}\right)$ events, 5 major and 1 minor air mass trajectory pattern were revealed by the cluster analysis (Figure 9$)$. The minor $\mathrm{BT}_{\mathrm{sp}}$ pattern $\left(\mathrm{BT}_{\mathrm{sp}} 6\right)$ is undoubtedly a hybrid of $\mathrm{BT}_{\mathrm{sp}} 5$. Table 1 shows the number of days belonging to each of the climatological and significant precipitation BT patterns and these are categorised further into BTs that originate from the east or west of DI. Climatologically, DI experiences passage of air masses from the east for $\sim 40 \%$ of the time. Similarly, $\sim 39 \%$ of the significant precipitation days are associated with air masses moving in from the east over the Weddell Sea. However, when 
the relative occurrence of specific $\mathrm{BT}$ patterns that are similar in the $\mathrm{BT}_{\mathrm{sp}}$ and $\mathrm{BT}_{\mathrm{cl}}$ plots (Figure 9) are compared, a greater proportion of significant precipitation days are associated with $\mathrm{BT}_{\mathrm{sp}} 2, \mathrm{BT}_{\mathrm{sp}} 3$ and, to a lesser extent, $\mathrm{BT}_{\mathrm{sp}} 4$ compared to climatology (Table 1). Conversely $\mathrm{BT}_{\mathrm{sp}} 1, \mathrm{BT}_{\mathrm{sp}} 5$ and $\mathrm{BT}_{\mathrm{sp}} 6$ are relatively unimportant in terms of significant precipitation days compared to their climatological occurrence (Table 1). The climatological importance of westerly atmospheric flow is demonstrated by the fact that respectively, six and three of the climatological and significant precipitation BT patterns are clearly associated with the circumpolar westerlies and thus the Circumpolar Trough (CPT).

The mean trajectories seen in the two sets of BT patterns are remarkably similar; in fact the only climatological BT pattern that does not have a significant precipitation equivalent is $\mathrm{BT}_{\mathrm{cl}} 3$ (Figure 9). Climatologically, $\mathrm{BT}_{\mathrm{cl}} 3$ is of almost equal importance to the other major $\mathrm{BT}$ patterns that originate to the west of $\mathrm{DI}\left(\mathrm{BT}_{\mathrm{cl}} 4\right.$ and $\left.\mathrm{BT}_{\mathrm{cl}} 5\right)$. All these westerly trajectories travel over the peninsula to reach DI and are associated with higher precipitation amounts on the western side of the peninsula than the eastern side due to orographic effects. Under such conditions DI would effectively lie in a precipitation shadow and thus rarely receive significant precipitation from these trajectories unless the air mass had acquired a large amount of moisture. $\mathrm{BT}_{\mathrm{cl}} 3$ displays a very short trajectory that will induce a much slower rate of moisture advection when compared to the longer westerly trajectories. Therefore an equivalent of $\mathrm{BT}_{\mathrm{cl}} 3$ is absent from the significant precipitation delivery mechanisms.

Despite the overall similarity of the climatological and significant precipitation BTs, some noteworthy differences do exist. The most striking of these is the generally higher curvature of the $\mathrm{BT}_{\mathrm{sp}}$. This most likely reflects the high relative vorticity of the flows within synoptic scale systems that are associated with significant precipitation at $\mathrm{DI} . \mathrm{BT}_{\mathrm{sp}} 2$ is a good example of this as its trajectory mimics the highly curved cyclonic path followed by air masses when cyclogenesis occurs in the western region of the Weddell Sea. Furthermore, $\mathrm{BT}_{\mathrm{sp}} 4$ and $\mathrm{BT}_{\mathrm{sp}} 5$, and $\mathrm{BT}_{\mathrm{sp}} 1$ and $\mathrm{BT}_{\mathrm{sp}} 2$ have origins further west and east respectively than their climatological equivalents. This may indicate that weather systems that bring significant precipitation to DI along such trajectories travel at much greater speeds than would be otherwise expected based on climatology. Another major difference is the smaller proportion of precipitation trajectories that come directly over the peninsula. This is an indication of moisture depleted air masses reaching DI via this route and its absence from the $\mathrm{BT}_{\mathrm{sp}}$ patterns that emerge is encouraging given the fact that the peninsula topography is smoothed in the model. This smoothing could have resulted in an artificially increased number of trajectories taking this route to DI than would happen in reality but this appears to have not had a significant impact on these trajectories, which start from the $850 \mathrm{hPa}$ level.

In addition to some basic differences in trajectory curvature and speed, subtle contrasts also exist between the climatological position of air mass origin and that for significant precipitation days (Figure 10). Air mass origin is defined here as the BT position 4 days before arrival at DI. This 4 day figure was chosen as a result of the work of Reijmer and van den Broeke (2001). They used back trajectories and associated moisture data from the ERA15 data to conclude that most of the moisture uptake for DML precipitation in 1998 occurred 3-5 days before the event. Therefore it is assumed that this is also the likely source of most of the DI precipitation. In terms of longitude (Figure 10), air mass trajectories associated with significant precipitation demonstrate an occurrence peak at approximately $2^{\circ}$ east of DI. This reflects the importance of significant precipitation trajectories associated with lee cyclogenesis east of the Antarctic Peninsula (Turner et al., 1998). Climatologically, a greater proportion of air masses originate further west compared to those associated with significant 
precipitation days. This may be explained by the dominance and high variability of synoptic scale activity in the CPT over the ABS (Connolley, 1997). Compared to longitudinal differences, the latitudinal contrast in air mass origin (Figure 10) is far greater between the climatology and significant precipitation timescales. For air masses associated with significant precipitation, the point of origin is approximately $5^{\circ}$ further north than the climatological position for all days. This not only indicates a more rapid poleward movement of systems associated with significant precipitation at DI but possible origin of these over warmer ocean surfaces or a smaller percentage of time spent over sea ice, both of which bear implications for vertical and, ultimately, horizontal moisture transport over DI. It is also evident from Figure 10 that the dominant latitudinal position of precipitation bearing air masses for DI four days before the event is between 50 and $70^{\circ} \mathrm{S}$.

In order to understand the relationship between the nature of the large scale pressure field and the back trajectories associated with significant precipitation, composite mean sea level pressure (MSLP) anomaly plots were constructed from the ERA-40 data for the six significant precipitation BTs (Figure 11). Pressure anomalies were calculated thus: the MSLP for the day of precipitation minus the monthly mean MSLP for the period 1979-1992 for the month that the significant precipitation day occurred. Associated with $\mathrm{BT}_{\mathrm{sp}} 1$ (Figure 11a) is a positive anomaly around most of Antarctica associated with a weak CPT. The strongest negative anomaly and the most significant feature of $\mathrm{BT}_{\mathrm{sp}} 1$ is over the Weddell Sea, indicative of a low pressure system in this region. This would imply that under these synoptic scale conditions precipitation would be delivered to DI by tracking from the South Atlantic and subsequently over the Weddell Sea. The trajectory taken by such systems is similar to the climatological path of mesocyclones that form in the eastern Weddell Sea (King and Turner, 1997). However, it is doubtful that the resolution of the ERA-40 grid will pick out any but the largest of these features so the precipitation is likely to be due to synoptic, or multiple meso-scale (Carleton, 1995), weather systems that advect moisture over DI from a north-easterly direction. The pressure anomaly pattern for $\mathrm{BT}_{\mathrm{sp}} 2$ (Figure $11 \mathrm{~b}$ ) demonstrates a slightly deeper CPT than that of $\mathrm{BT}_{\mathrm{sp}} 1$. However, the largest negative and most significant anomaly is over the Bellingshausen Sea. This anomalously low pressure also extends over the peninsula into the Weddell Sea. This pattern most likely represents lee cyclogenesis over the Weddell Sea. The mean trajectory of air masses associated with this pressure configuration would appear to support such a contention. For $\mathrm{BT}_{\mathrm{sp}} 3$ (Figure 11c), a CPT of comparable strength and character to that of $\mathrm{BT}_{\mathrm{sp}} 2$ is evident. The greatest difference between $\mathrm{BT}_{\mathrm{sp}} 2$ and $\mathrm{BT}_{\mathrm{sp}} 3$ is that the low over the Bellingshausen Sea associated with $\mathrm{BT}_{\mathrm{sp}} 3$ does not extend as far into the Weddell Sea region as that seen for $\mathrm{BT}_{\mathrm{sp}} 2$. As such, the trajectories associated with $\mathrm{BT}_{\mathrm{sp}} 3$ originate over the Bellingshausen Sea and track over the northern tip of the peninsula. They subsequently move around the small area of low pressure over the Weddell Sea and move towards DI. This BT pattern therefore exhibits some characteristics of lee cyclogenesis but also of weather systems moving towards DI via a weak westerly circumpolar circulation. To some extent, $\mathrm{BT}_{\mathrm{sp}} 1-3$ are all associated with a high/low pressure couplet across the peninsula. Such a pressure configuration resembles that observed around the Antarctic Peninsula during El Niño (i.e. ENSO warm) events (Turner, 2004). In relation to this, the number of $\mathrm{BT}_{\mathrm{sp}} 1-3$ events per year demonstrates inter-annual variability worthy of note (Figure 12). $\mathrm{BT}_{\mathrm{sp}} 2$ appears to oscillate with a wavelength of about 4 years with frequency peaks at 1982-3, 1987 and 1991 which all coincide with El Niño events from the Southern Oscillation Index of Stocker et al. (2001). Although possessing much less pronounced inter-annual variation, the frequency of $\mathrm{BT}_{\mathrm{sp}} 1$ and $\mathrm{BT}_{\mathrm{sp}} 3$ also appear to peak around the time of El Niño events. These observations are in line with those made above concerning the nature of El Niño related pressure anomalies. 
The pressure anomaly patterns for $\mathrm{BT}_{\mathrm{sp}} 4,5$ and 6 (Figures 11d-f) are characterized by an increasingly more deep CPT in the Amundsen-Bellingshausen Sea (ABS) region for each case. This also indicates increasingly strong circumpolar westerly air flows. These westerly trajectories lie over the South Pacific and originate at greater distances from DI in each successive case. In contrast to the situation for $\mathrm{BT}_{\mathrm{sp}} 1-3$, the pattern of anomalously low pressure over the ABS bears some similarity to that observed over the western Antarctic region during La Niña (i.e. ENSO cold) events (Turner, 2004). Such events appear to have an impact on the joint frequency of $\mathrm{BT}_{\mathrm{sp}} 4,5$ and 6 (Figure 12) as marked increases in the frequency of the BTs originating over the ABS occurred in 1985 and 1989, coincident with pronounced La Niña events. Conversely frequency troughs occurred in 1983, 1987 and 1990-1992 when El Niño conditions dominated the Pacific Basin.

One objective of this study was to establish whether the inter-annual variability of air mass trajectories influences the annual accumulation at DI. Although correlation analysis revealed no statistical association between the frequencies of individual BTs associated with significant precipitation events and the ERA-40 or ice core based accumulation, significant relationships were found between DI accumulation and the climatological occurrence of BT frequencies. For example, of the climatological BT patterns, DI accumulation appears to be most sensitive to the occurrence $\mathrm{BT}_{\mathrm{cl}} 1$ and $\mathrm{BT}_{\mathrm{cl}} 4$. In the former case, the association is positive $(r=0.56, p=0.04)$ such that on an annual basis a greater frequency of air masses from the Weddell Sea results in higher accumulation at DI as recorded in the ice core accumulation. In contrast, a greater occurrence of air masses originating over the ABS is associated with low annual ERA-40 accumulation $(\mathrm{r}=-0.51, \mathrm{p}=0.05)$. The physical explanation for such associations is clearly seen in the MSLP anomalies associated with the significant precipitation equivalent of $\mathrm{BT}_{\mathrm{cl}} 1$ and $\mathrm{BT}_{\mathrm{cl}} 4$ (Figures $11 \mathrm{a}$ and 11d). The occurrence of $\mathrm{BT}_{\mathrm{sp}} 1 / \mathrm{BT}_{\mathrm{cl}} 1$ is associated with negative pressure anomalies over the Weddell Sea and, thus, cyclogenesis. At the same time, positive pressure anomalies and anomalous subsiding southerly flows are obtained over the ABS (Figure 11a), the consequence of which will be a weakened CPT and few eastward travelling weather systems originating from this region. Conversely, a high frequency of $\mathrm{BT}_{\mathrm{sp}} 4 / \mathrm{BT}_{\mathrm{cl}} 4$ is associated with anomalous low pressure over the ABS indicative of an active CPT. Simultaneously, over the Weddell Sea, a strong blocking situation occurs which will prevent the movement over DI of any moisture bearing systems originating west of the peninsula, the consequence of which will be low annual accumulation. This implies that annual accumulation is more a product of the daily variation of air mass delivery and not just the air masses associated with large precipitation events.

Given the association between synoptic activity over the Weddell Sea and ABS, of interest is the trend in the location of air mass origin as it relates to accumulation at DI. As noted earlier, statistically significant positive trends are evident for both the ERA-40 and the ice core accumulation for 1979-1992. These are matched by a statistically significant decline in the occurrence of $\mathrm{BT}_{\mathrm{cl}} 4$ over the same period. Based on the pressure anomaly patterns evident in Figures 11a and 11d, this would imply a sustained weakening of synoptic activity over the ABS and thus enhanced cyclonic and/or reduced blocking activity over the Weddell Sea. The outcome of this would be increasing annual accumulation totals as shown for the study period.

\section{Discussion and Conclusions}


The principal goal of this study was to shed light on the precipitation delivery mechanisms for DI. In order to achieve this, a back trajectory analysis of ERA-40 significant precipitation events (i.e. the largest events that deliver $50 \%$ of the total precipitation) was undertaken. Back trajectory patterns for such events were subsequently compared with the climatological pattern in order to establish if differences in BT pattern characteristics exist between climatology and significant precipitation days. Study results have revealed that, at the general level, there appears to be little difference in BT patterns between climatology and significant precipitation events with both showing air masses arriving from the South Atlantic, South Pacific and the Weddell Sea. However, subtle differences are apparent. Compared to the climatological pattern of air mass trajectories arriving over DI, significant precipitation events appear to be associated with faster moving air masses and, therefore, possibly greater rates of moisture advection over DI. Furthermore, these air masses take a much less direct route to DI as they follow a highly curved trajectory. This implies that the flows that deliver significant precipitation amounts to DI possess high relative vorticity, and also that they do not traverse the highest regions of the Antarctic Peninsula. A further noteworthy characteristic is the importance of easterly air mass trajectories for significant precipitation events, implying that the Weddell Sea region is an important source of moisture for accumulation over DI. This is an important finding given the dominance of the circumpolar westerlies over the wider study area (Reijmer et al., 2002). Further, it is proposed that the dominant latitudinal source of precipitation bearing air masses for DI is between the latitudes of $50-70^{\circ} \mathrm{S}$.

Regarding the implications of the precipitation delivery mechanisms that were discovered here, it has been proposed that western Antarctic precipitation will harbour a particularly strong ENSO signature because of its location relative to the Pacific Ocean (Turner, 2004). Several studies have reported these ENSO links with Antarctica in certain precipitation data sets; Cullather et al. (1996) in the ECMWF operational analyses (or EOP); Noone et al. (1999) in ERA-15 and ice core accumulation; Bromwich et al. (2000) in EOP and ERA-15; Marshall (2000) in ERA-15; Genthon et al. (2003) in the NCEP-NCAR re-analysis, ERA-15, GCM and satellite data; Genthon and Cosme (2003) in ERA-40; and Turner (2004) summarises the signals observed in ice cores. In this paper, a signature of ENSO is highlighted in the precipitation delivery mechanisms for DI via the frequency of occurrence of precipitation events from the east (west) of DI during El Niño (La Niña) events.

Given the nature of the pressure anomaly fields associated with easterly air masses arriving at DI, it would appear that lee cyclogenesis plays an important role in precipitation delivery to DI. This corroborates the satellite image based findings of Turner et al. (1998) who concluded that the frequent occurrence of low pressure systems developing in the lee of the peninsula possessed the potential to deliver significant precipitation amounts to the study area. Although significant precipitation delivery from the east via lee cyclogenesis is important for the precipitation climatology at DI, equally important are air masses that have originated to the west of the peninsula. Accordingly, activity within the CPT also appears to play a role in precipitation delivery to DI as approximately $60 \%$ of significant precipitation events have air mass trajectories that can be traced back to the ABS (Table 1).

In relation to the importance of the ABS for the precipitation regime at DI is the intriguing finding that there appears to be a trend to an increasing number of significant precipitation events over DI that have origins over the ABS. However at the climatological scale, the number of air masses arriving at DI from the general region of the ABS appears to be 
decreasing. This apparently contradictory finding may indicate that although fewer air masses may arrive at DI from the west, the ones that do are delivering greater amounts of precipitation than otherwise might be expected. Such a trend may be associated with a deepening of the CPT, which, in turn, is influenced by the Southern Annual Mode (SAM). The fact that the SAM has demonstrated a positive trend over recent years (Marshall, 2003), and that this trend explains approximately $20 \%$ of the variation $(r=0.45, p=0.05)$ in the joint frequency of trajectories originating over the ABS associated with significant precipitation at DI (BT $\left.\mathrm{BP}_{\mathrm{sp}} 4-6\right)$, indicates a possible linkage between CPT dynamics and DI accumulation. However, such a contention will have to await an analysis of the trend of the actual precipitation amounts associated with air masses originating over the ABS. Such an analysis would also assist with an interpretation of the inter-annual variability of accumulation at DI as recorded by ERA-40 and the DI ice core, as it has been suggested in this study that the frequency of significant precipitation events alone cannot explain such variability.

The SAM also appears to have had an impact on the annual precipitation totals at DI. The positive trend in annual precipitation totals in the ERA-40 data is a result of an increase in the size of the summer precipitation events - it is also during summer that the greatest positive trends in the SAM have been observed (Marshall, 2003). This connection deserves more investigation in the future via a seasonal analysis of the BT data.

A major assumption of this study is that ERA-40 and the DI ice core offer a realistic picture of the accumulation regime at DI. For the study period of 1979-1992 the estimates of annual accumulation from ERA-40 and the ice core are quite well correlated, however, for the duration of ERA-40 this is not so and is of concern. This is either indicative of the unreliability of ERA-40 for making estimates of accumulation before 1979 related to more fundamental problems in the re-analysis (Bromwich and Fogt, 2004) and/or the nonrepresentativeness of the accumulation record contained within the single DI ice core. In the case of ERA-40, topographic and sea/land classification inaccuracies in the re-analysis model, as well as the fact that the ERA-40 forecasts represent a whole grid cell, may all contribute to unreliable estimates of DI accumulation. These factors are over and above the problems already discussed that are attributed to the re-analysis before the introduction of satellite data. Possible problems with the ice core record also need to be acknowledged. These include the method by which the accumulation record has been partitioned into annual totals (based on the troughs in the ice core isotope stratigraphy being assigned as the beginning of August), in situ snow/ice melt and accumulation that occurs as a result of local microclimatic effects.

Despite the above concerns, study results have shown that the climatological occurrences of BT patterns are able to account for a significant proportion of the variation in annual accumulation at DI as represented by ERA-40 and the DI ice core. This is an interesting result with respect to the lack of understanding of the precipitation regime in this area of the eastern Antarctic Peninsula. It also implies that it would be of interest for future work of this sort, in this region, to investigate the impact of precipitation events using a lower threshold than the significant precipitation event used in this paper.

In summary, the key centres of action of precipitation delivery for DI appear to be the Weddell Sea Region to the east and the ABS to the west of DI. Although this study has shown that an association between BT pattern frequency and DI accumulation is plausible on physical grounds, further testing of this hypothesis will have to await an analysis of BT- 
accumulation associations for the full period of ERA-40 data that is suitably reliable. Restriction of the BT analysis to the years of overlap between the ERA-15 data and the ice core has also restricted conclusions being drawn regarding sympathetic frequency trends of accumulation and BT patterns. For example, that the weakly positive, but statistically insignificant, trend in the frequency of BTs with origins over the ABS associated with significant precipitation at DI may be part of a longer term climatic oscillation.

\section{Acknowledgements}

We would like to thank the BADC for their help in providing the backwards air trajectory data and Rob Mulvaney of the British Antarctic Survey for making the Dolleman Island ice core data available. The useful comments of the two reviewers of this work also need to be acknowledged. 


\begin{tabular}{|c|c|c|c|c|c|c|c|c|}
\hline Cluster & 1 & 2 & 3 & 4 & 5 & 6 & 7 & 8 \\
\hline & $=\mathrm{Fr}$ & & & & Fro & est & & \\
\hline \multirow[t]{3}{*}{$\mathrm{BT}_{\mathrm{sp}}$} & 51 & 211 & 188 & 147 & 53 & 4 & & \\
\hline & $7.8 \%$ & $32.3 \%$ & $28.7 \%$ & $22.5 \%$ & $8.1 \%$ & $0.6 \%$ & & \\
\hline & $\overline{=} 4$ & & & 5 & & & & \\
\hline \multirow[t]{2}{*}{$\mathrm{BT}_{\mathrm{cl}}$} & 792 & 1091 & 823 & 962 & 1038 & 38 & 44 & 58 \\
\hline & $16.3 \%$ & $22.5 \%$ & $17.0 \%$ & $19.9 \%$ & $21.4 \%$ & $0.8 \%$ & $0.9 \%$ & $1.2 \%$ \\
\hline
\end{tabular}

Table 1. The number of days that fell into the clusters of significant precipitation days $\left(\mathrm{BT}_{\mathrm{sp}}\right)$ and the climatological timescale $\left(\mathrm{BT}_{\mathrm{cl}}\right)$. 


\section{References}

Bromwich, D. H. and Weaver, C. J. 1983. Latitudinal displacement from main moisture source controls $\delta^{18} \mathrm{O}$ of snow in coastal Antarctica. Nature 301, 145-147.

Bromwich, D. H., Rogers, A. N., Kållberg, P., Cullather, R. I., White, J. W. C. and Kreutz, K. J. 2000. ECMWF analyses and reanalyses depiction of ENSO signal in Antarctic precipitation. J. Clim. 13, 1406-1420.

Bromwich D. H. and Fogt R. L. 2004. Strong trends in the skill of the ERA-40 and NCEP/NCAR reanalyses in the high and middle latitudes of the Southern Hemisphere, 19582001. J. Clim. in press

Carleton, A. M. 1995. On the interpretation and classification of mesoscale cyclones from satellite IR imagery. Int. J. Rem. Sens. 16, 2457-2485.

Ciais, P., White, J. W. C., Jouzel, J. and Petit, J. R. 1995. The origin of present-day Antarctic precipitation from surface snow deuterium excess data. J. Geophys. Res. 100, D9, 1891718927.

Connolley, W. M. 1997. Variability in annual mean circulation in the southern high latitudes. Cli. Dyn. 13, 745-756.

Cullather, R. I., Bromwich, D. H. and van Woert, M. L. 1996. Interannual variations in Antarctic precipitation related to El Niño southern oscillation. J. Geophys. Res. 101, D14, 19109-19118.

De Angelis, H. and Skvarca, P. 2003. Glacier surge after Ice Shelf collapse. Science 299, $1560-1562$.

Delaygue, G., Jouzel, J., Masson, V., Koster, R. D. and Bard, E. 2000a. Validity of the isotopic thermometer in central Antarctica: limited impact of glacial precipitation seasonality and moisture origin. Geophys. Res. Lett. 27, 2677-2860.

Delaygue, G., Masson, V., Jouzel, J., Koster, R. D. and Healy, R. J. 2000b. The origin of Antarctic precipitation: a modelling approach. Tellus 52B, 19-36.

Doake, C. S. M., Corr, H. F. J., Rott, H., Skvarca, P. and Young, N. W. 1998. Breakup and conditions for stability of the northern Larsen Ice Shelf. Nature 391, 778-780.

Folland, C. K., Karl, T. R., Christy, J. R., Clarke, R. A., Gruza, G. V., Jouzel, J., Mann, M. E., Oerlemans, J., Salinger, M. J. and Wang, S.-W. 2001. Observed Climate Variability and Change. In: Climate Change 2001: The Scientific Basis. Contribution of Working Group I to the Third Assessment Report of the Intergovernmental Panel on Climate Change (eds. J. T. Houghton, Y. Ding, D. J. Griggs, M. Noguer, P. J. van der Linden, X. Dai, K. Maskell, and C. A. Johnson). Cambridge University Press, Cambridge, United Kingdom and New York, NY, USA, 99-182.

Genthon, C., 2003. Climate and surface mass balance of the polar ice sheets in ERA40/ERA15. ECMWF Re-analysis Project Report Series 3, 299-316. 
Genthon, C. and Braun, A. 1995. ECMWF analyses and predictions of the surface climate of Greenland and Antarctica. J. Clim. 8, 2324-2332.

Genthon, C. and Krinner, G. 1998. Convergence and disposal of energy and moisture on the Antarctic polar cap from ECMWF reanalyses and forecasts. J. Clim. 11, 1703-1716.

Genthon, C. and Cosme, E. 2003. Intermittent signature of ENSO in west-Antarcitc precipitation. Geophys. Res. Lett. 30, 2081, doi:10.1029/2003GL018280.

Genthon, C., Krinner, G. and Sacchettini, M. 2003. Interannual Antarctic tropospheric circulation and precipitation variability. Cli. Dyn. 21, 289-307.

King, J. C. and Turner, J. 1997. Antarctic meteorology and climatology. Cambridge University Press, Cambridge, 425 pp.

Krinner, G. and Genthon, C. 1999. Altitude dependence of the ice sheet surface climate. Geophys. Res. Lett. 26, 2227-2230.

Legrand, M. and Mayewski, P. 1997. Glaciochemistry of polar ice cores: a review. Rev. Geophys. 35, 219-243.

Marshall, G. J. 2000. An examination of the precipitation regime at Thurston Island, Antarctica, from ECMWF re-analysis data. Int. J. Climatol. 20, 255-277.

Marshall, G. J. 2003. Trends in the Southern Annular Mode from observations and analyses. J. Clim. 16, 4134-4143.

Mulvaney, R., Oerter, H., Peel, D. A., Graf, W., Arrowsmith, C., Pasteur, E. C., Knight, B., Littot, G. C. and Miners, W. D. 2002. 1000 year ice-core records from Berkner Island, Antarctica. Ann. Glaciol. 35, 45-51.

Noone, D., Turner, J. and Mulvaney R. 1999. Atmospheric signals and characteristics of accumulation in Dronning Maud Land, Antarctica. J. Geophys. Res. 104, D16, 19191-19211.

Pasteur, E. C. and Mulvaney, R. 2000. Migration of methane sulphonate in Antarctic firn and ice. J. Geophys. Res. 105, D9, 11525-11534.

Peel, D. A. 1992. Ice core evidence from the Antarctic Peninsula region. In: Climate since A.D. 1500 (eds. R. S. Bradley and P. D. Jones). Routledge, London, 549-571.

Peel, D. A., Mulvaney, R. and Davison, B. M. 1988. Stable-isotope/air-temperature relationships in ice cores from Dolleman Island and the Palmer Island plateau, Antarctic Peninsula. Ann. Glaciol. 10, 130-136.

Peel, D. A. and Mulvaney, R. 1992. Time-trends in the pattern of ocean-atmosphere exchanges in an ice core from the Weddell Sea sector of Antarctica. Tellus 44B, 430-442. 
Rankin, A. M., Wolff, E. W. and Martin, S. 2002. Frost flowers: Implications for tropospheric chemistry and ice core interpretation. J. Geophys. Res. 107, D23, 4683, doi:10.1029/2002JD002492

Reijmer, C. H. and van den Broeke, M. R. 2001. Moisture source of precipitation in Western Dronning Maud Land, Antarctica. Antarctic Sci. 13, 210-220.

Reijmer, C. H., van den Broeke, M. R. and Scheele, M. P. 2002. Air parcel trajectories and snowfall related to five deep drilling locations in Antarctica based on the ERA-15 dataset. $J$. Clim. 15, 1957-1968.

Rott, H., Rack, W., Skvarca, P. and De Angelis, H. 2002. Northern Larsen Ice Shelf, Antarctica: further retreat after collapse. Ann. Glaciol. 34, 277-282.

Schlosser, E. 1999. Effects of seasonal variability of accumulation on yearly mean $\delta^{18} \mathrm{O}$ values in Antarctic snow. J. Glaciol. 45, 463-468.

Simmonds, I., Keay, K. and Lim, E.-P. 2003. Synoptic activity in the seas around Antarctica. Mon. Wea. Rev. 131, 272-288.

Skvarca, P., Rack, W., Rott, H. and Donángelo, T. I. Y. 1998. Evidence of recent climatic warming on the eastern Antarctic Peninsula. Ann. Glaciol. 27, 628-632.

Stocker, T. F., Clarke, G. K. C., Le Treut, H., Lindzen, R. S., Meleshko, V. P., Mugara, R. K., Palmer, T. N., Pierrehumbert, R. T., Sellers, P. J., Trenberth, K. E. and Willebrand, J. 2001. Physical Climate Processes and Feedbacks. In: Climate Change 2001: The Scientific Basis. Contribution of Working Group I to the Third Assessment Report of the Intergovernmental Panel on Climate Change (eds. J. T. Houghton, Y. Ding, D. J. Griggs, M. Noguer, P. J. van der Linden, X. Dai, K. Maskell, and C. A. Johnson). Cambridge University Press, Cambridge, United Kingdom and New York, NY, USA, 417-470.

Torinesi, O., Fily, M. and Genthon, C. 2003. Variability and trends of the summer melt period of Antarctic ice margins since 1980 from microwave sensors. J. Clim. 16, 1047-1060.

Turner, J. 2004. The El Niño-Southern Oscillation and the Antarctic. Int. J. Climatol. 24, $1-31$.

Turner, J., Lachlan-Cope, T. A., Thomas, J. P. and Colwell, S. R. 1995. The synoptic origins of precipitation over the Antarctic Peninsula. Antarctic Sci. 7, 327-337.

Turner, J., Colwell, S. R. and Harangozo, S. A. 1997. Variability of precipitation over the coastal western Antarctic Peninsula from synoptic observations. J. Geophys. Res. 102, D12, 13999-14007.

Turner, J., Marshall G. J. and Lachlan-Cope, T. A. 1998. Analysis of synoptic-scale low pressure systems within the Antarctic Peninsula sector of the circumpolar trough. Int. J. Climatol. 18, 253-280. 
Turner, J., Connolley, W. M., Leonard, S., Marshall, G. J. and Vaughan, D. G. 1999. Spatial and temporal variability of net snow accumulation over the Antarctic from ECMWF reanalysis project data. Int. J. Climatol. 19, 697-724.

Vaughan, D. G., Bamber, J. L., Giovinetto, M., Russell, J. and Cooper, A. P. R. 1999. Reassessment of net surface mass balance in Antarctica. J. Clim. 12, 933-946.

Vaughan, D. G., Marshall, G. J., Connolley, W. M., King, J. C. and Mulvaney, R. 2001. Devil in the detail. Science 293, 1777-1779.

Wolff, E. W., Rankin, A. M. and Röthlisberger, R. 2003. An ice core indicator of Antarctic sea ice production? Geophys. Res. Lett. 30, 2158, doi: 10.1029/2003GL018454.

Yarnal, B., Comrie, A. C., Frakes, B. and Brown, D. P. 2001. Developments and prospects in synoptic climatology. Int. J. Climatol. 21, 1923-1950. 


\section{Figures}

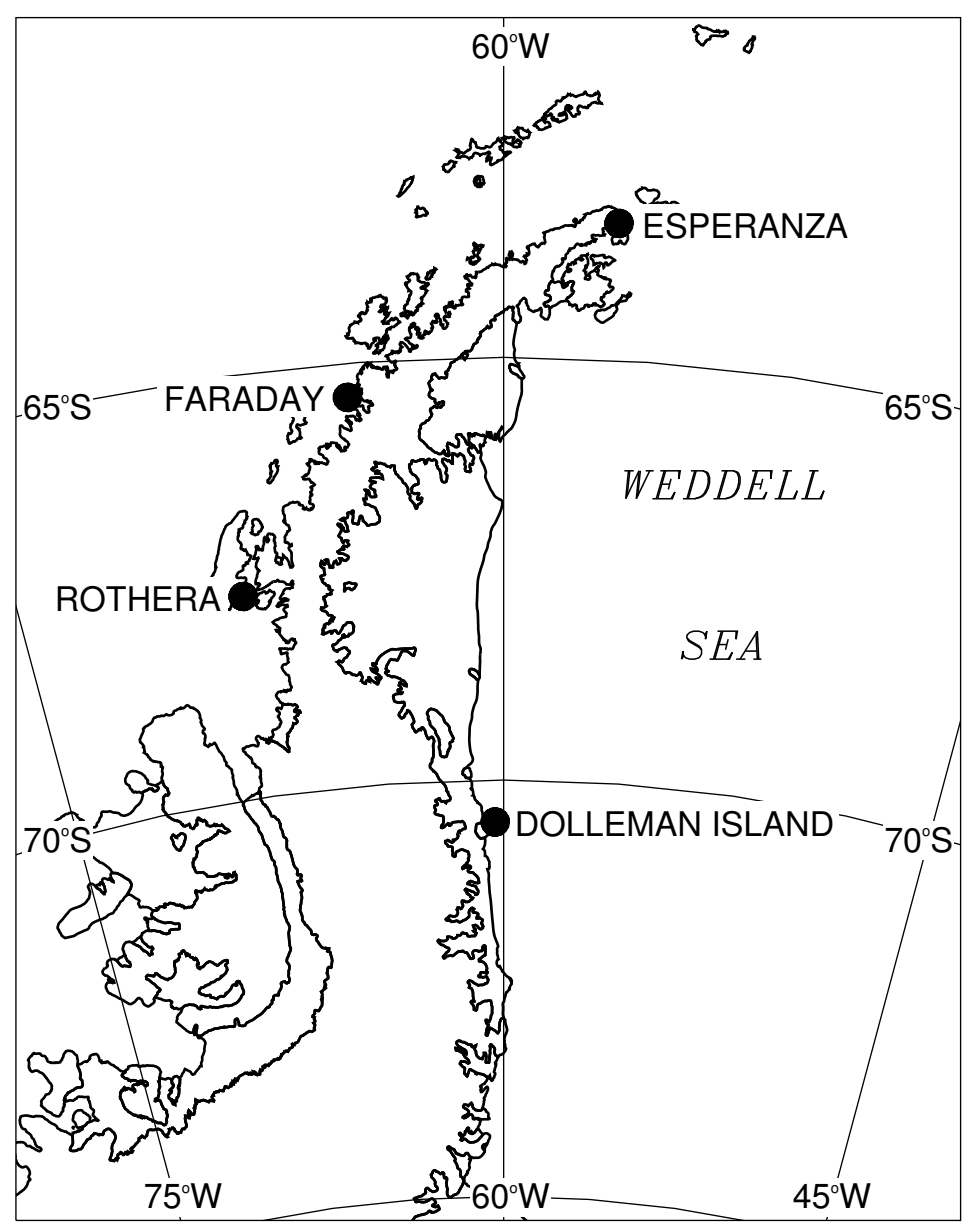

Fig. 1. Map of the Antarctic Peninsula showing the location of places referred to in the text. 


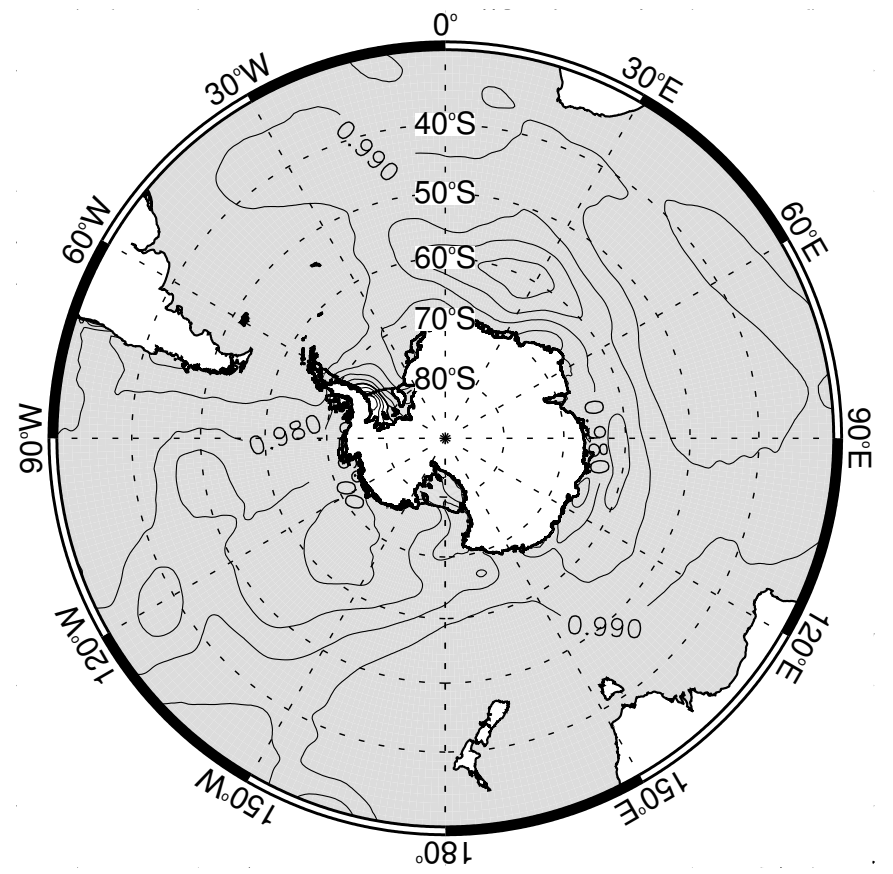

Fig. 2. A plot of the correlation co-efficient between the monthly MSLP for 1979-1992 from the ERA-15 and ERA-40 re-analyses for the Southern Hemisphere. Shaded areas are where $r$ $>0.95$. The correlations are significant at the 0.01 level for the whole hemisphere. 


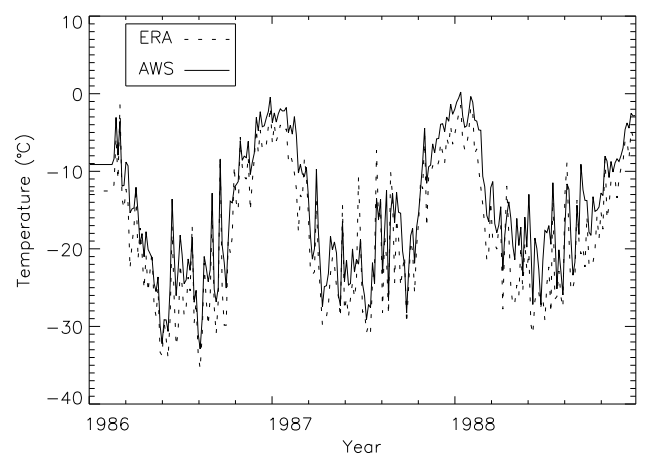

Fig. 3. Plot of daily mean temperature from the DI AWS (solid line) and the ERA-40 data (dashed line).

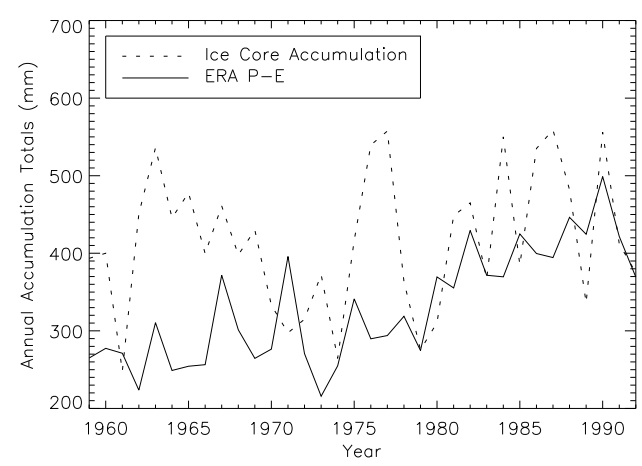

Fig. 4. Comparison of the ice core accumulation (dashed line) and the ERA-40 P-E (solid line).

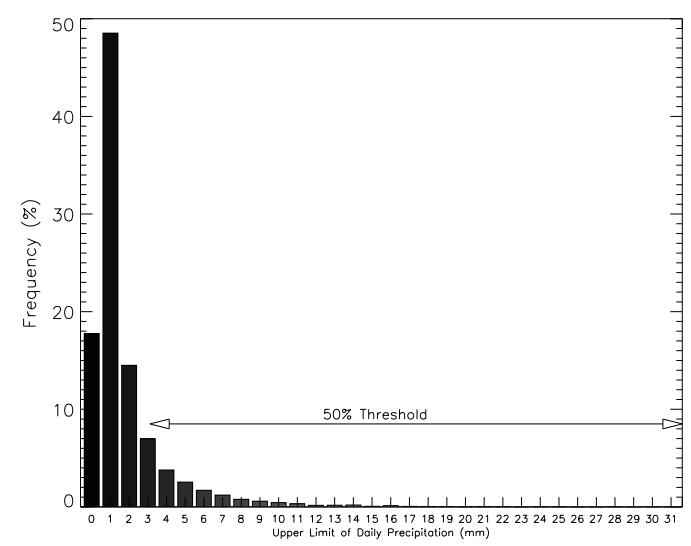

Fig. 5. Frequency of precipitation events from the ERA-40 data set for 1979-1992. After the first bar, each bar represents the number of events in the $311 \mathrm{~mm}$ precipitation bins as a percentage of all the days in the 1979-92 range. The first bar represents days that receive no precipitation. The horizontal arrow highlights the range of the largest events that contribute $50 \%$ of the total precipitation at DI. 


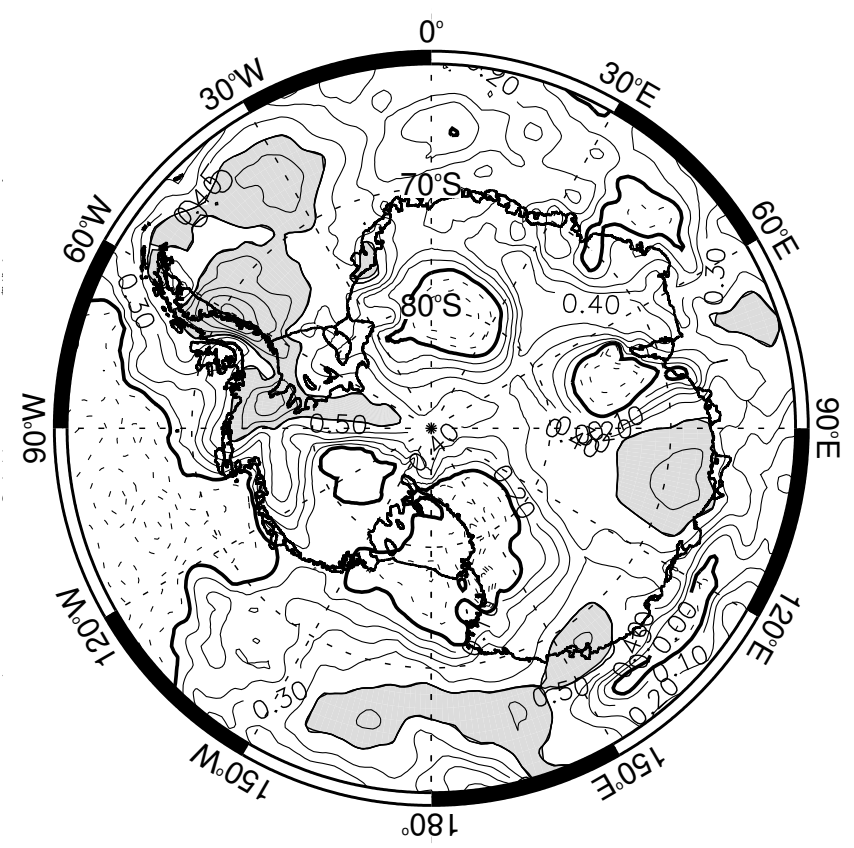

Fig. 6. A plot of the correlation co-efficient between the annual mean ERA-40 accumulation (P-E) at DI and at all other ERA grid cells in the Antarctic region for 1979-1992. The correlations are significant at the 0.01 level for all of the Peninsula and Weddell Sea area but are less significant throughout the rest of the plot. Dashed lines represent $r<0$ and shaded areas where $r>0.5$. 


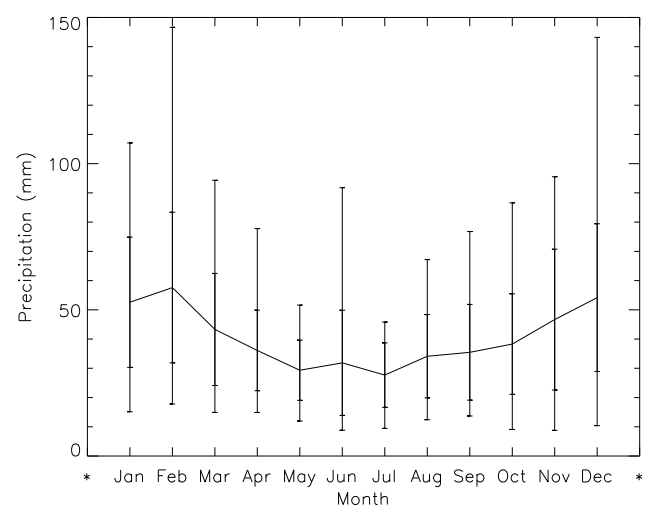

Fig. 7. The annual cycle of precipitation at DI from the ERA-40 re-analysis. The error bars represent standard deviation and the range for each month over the 14-year study period.
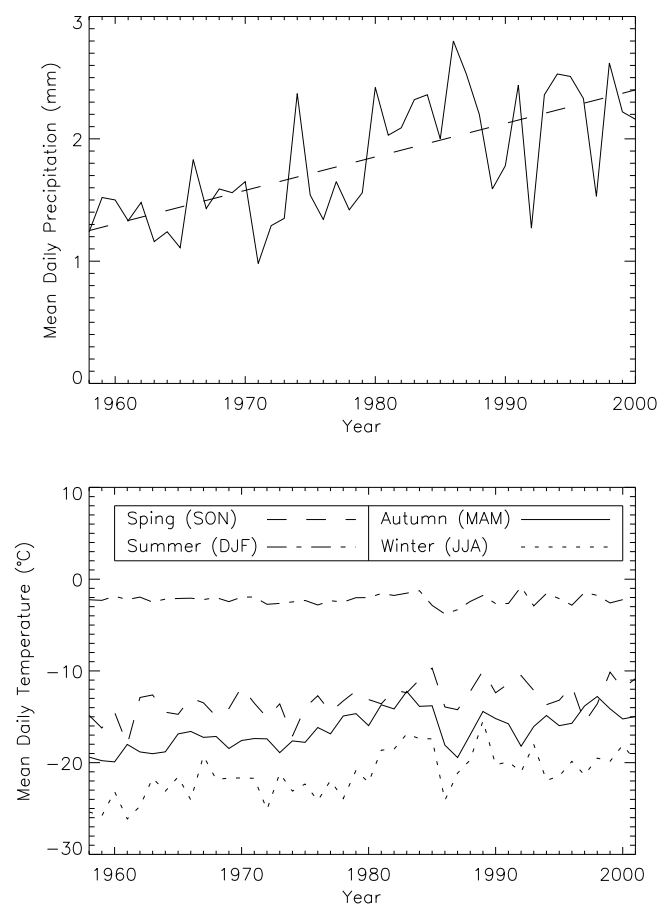

Fig. 8. Mean daily precipitation for the summer (DJF) at DI from ERA-40 (top) and mean daily temperature for the four seasons at DI from the ERA-40 re-analysis (bottom). 

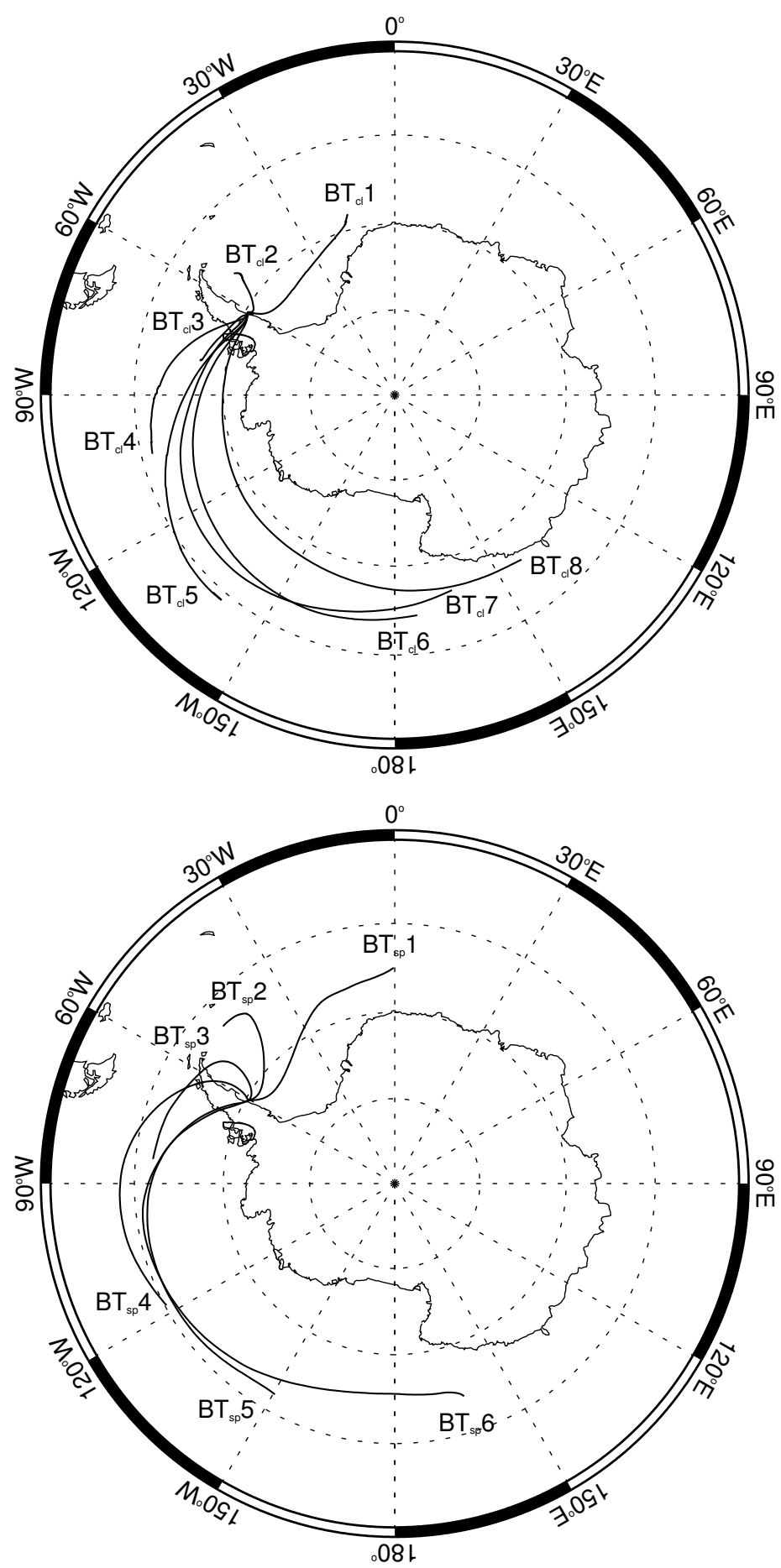

Fig. 9. Means of the 5-day backwards trajectories that fell into each cluster found in the cluster analysis performed on the climatology trajectories (top) and the 654 significant precipitation trajectories (bottom). 

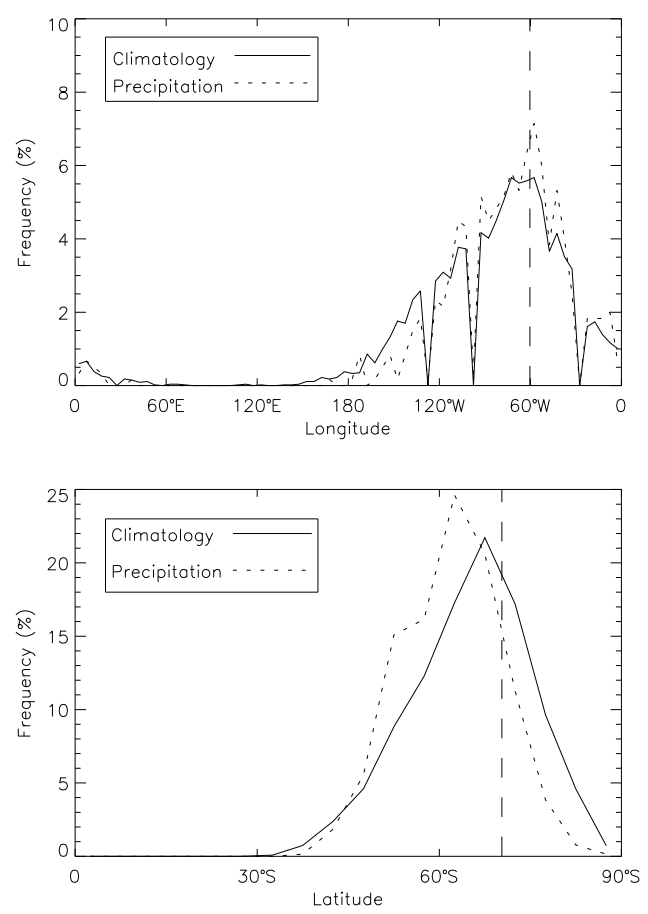

Fig. 10. Plots to show the longitudinal (top) and latitudinal (bottom) position of the precipitation trajectories 4 days before they arrive at DI. The vertical dashed line shows the longitude/latitude of DI. 

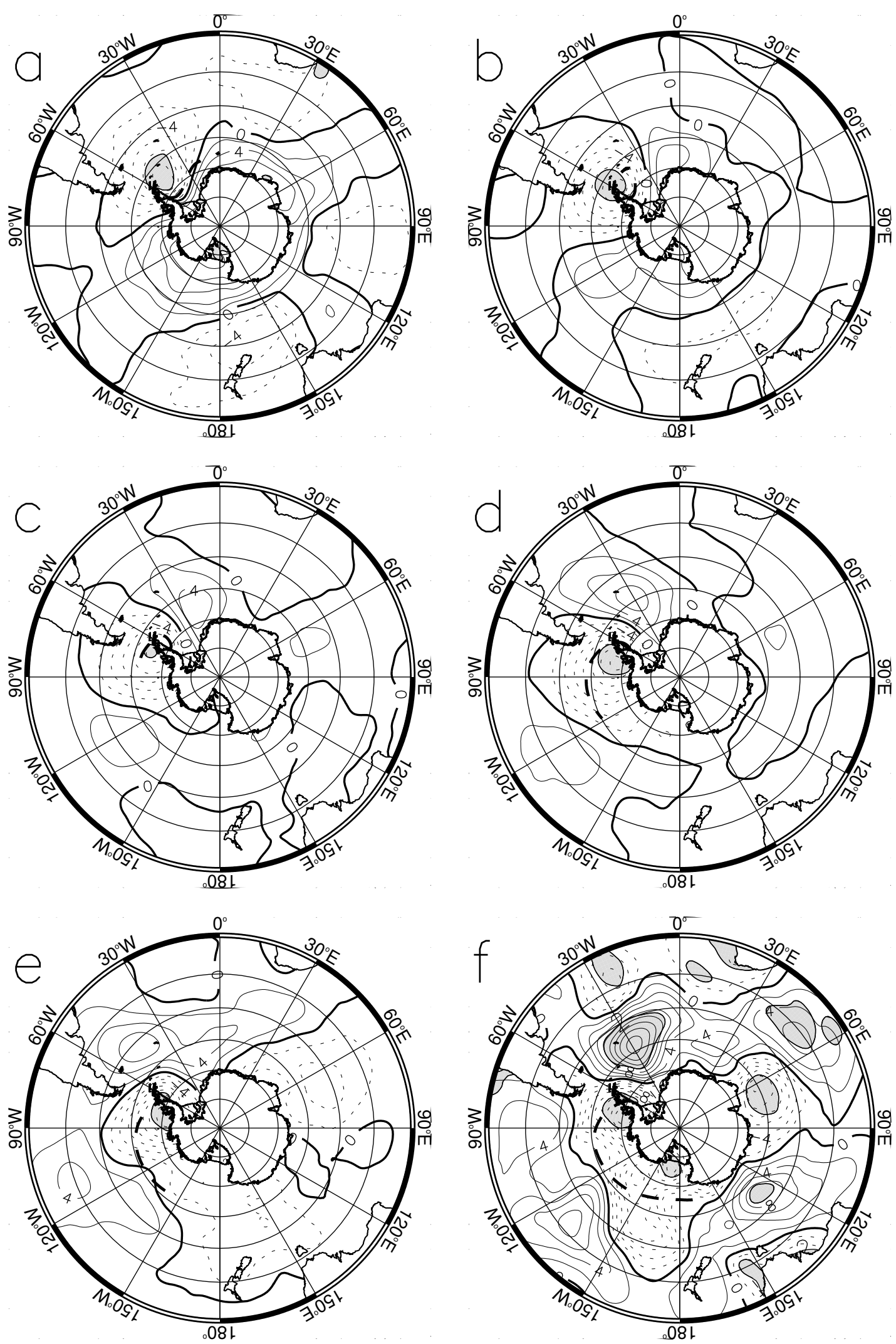

Fig. 11. The mean MSLP anomalies of the days that fell into each cluster of significant precipitation events. They are presented separately for $\mathrm{BT}_{\mathrm{sp}} 1-6$ in Figures $11 \mathrm{a}-\mathrm{f}$ respectively. Dashed contours show negative anomalies and the shaded areas are significant (i.e. those areas that fall outside the mean \pm 2 standard deviations). The thick dashed line in each plot is the mean backwards trajectory for the members of each cluster (see Figure 9 (bottom)). 

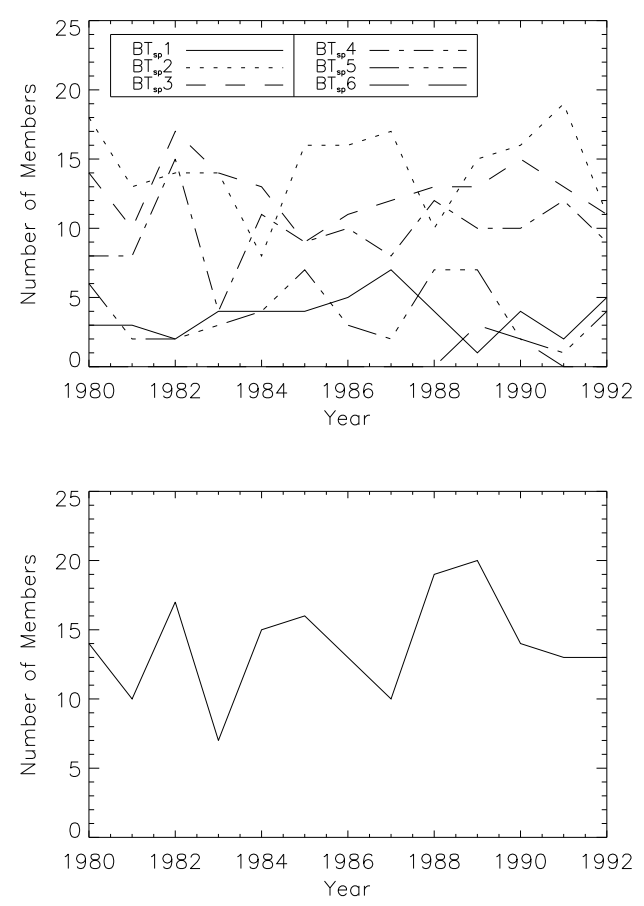

Fig. 12. Plots to show the number of trajectories that fell into each of the $6 \mathrm{BT}_{\mathrm{sp}}$ clusters for each year (top) and the sum of the annual number of members of $\mathrm{BT}_{\mathrm{sp}} 4,5$ and 6 (bottom). 